\title{
Removal of tetracycline from aqueous solution using Fe-doped zeolite
}

\author{
M. H. Jannat Abadi' S. M. M. Nouri' ${ }^{2}$ (D) R. Zhiani ${ }^{3,4}$ H. D. Heydarzadeh² $\cdot$ A. Motavalizadehkakhky
}

Received: 1 October 2018 / Accepted: 27 June 2019 / Published online: 16 July 2019

(c) The Author(s) 2019

\begin{abstract}
Tetracycline is one of the most widely used antibiotics that causes contamination of aqueous environments and has raised serious concern during the past few years. In this work, adsorption of tetracycline on a modified zeolite was studied through a batch system. Synthetic zeolite $13 \mathrm{X}$ was modified using Fe(III). The results show that the removal efficiency of tetracycline by modified zeolite has considerably increased. Different experiments were carried out in order to analyze the effect of parameters such as $\mathrm{pH}$, initial concentration of tetracycline, time, etc. The results indicate that tetracycline adsorption on the zeolite strongly depends on the $\mathrm{pH}$ of the solution due to amphoteric functional groups of tetracycline and maximum adsorption capacity of tetracycline by modified zeolite with a pH of approximately 6 . The Langmuir isotherm shows good agreement with the experimental data suggesting monolayer adsorption. Maximum adsorption capacity of the modified zeolite reached at the experiments is almost $200 \mathrm{mg} / \mathrm{g}$. XRD, XRF and FTIR results confirm the existence of the Fe phase in the zeolite texture. Amide groups of TC were responsible for the complexation with $\mathrm{Fe}^{3+}$. Also, tetracycline removal was studied in a continuous column to simulate an industrial waste water process.
\end{abstract}

Keywords Tetracycline removal $\cdot$ Adsorption $\cdot$ Modified zeolite $\cdot$ Fe-doped sorbent

\section{Introduction}

Tetracyclines (TC) are a broad spectrum class of antibiotics and are widely used for veterinary and human health purposes [1]. A large portion of antibiotics is transmitted from the body to excretion without modification. Excessive use of antibiotics, improper disposal, and lack of policy regulations pose a serious environmental and health concern [2].

Constant exposure to antibiotics in the environment not only disturbs natural ecological processes but can also be

S. M. M. Nouri

m.nouri@hsu.ac.ir

1 Chemical Engineering Department, Islamic Azad University, Neyshabur Branch, Neyshabur, Iran

2 Chemical Engineering Department, Hakim Sabzevari University, Sabzevar 9617976487, Iran

3 Young Researchers and Elite Club, Islamic Azad University, Neyshabur Branch, Neyshabur, Iran

4 Chemistry Department, New Materials Technology and Processing Research Center, Islamic Azad University, Neyshabur Branch, Neyshabur, Iran

5 Chemistry Department, Islamic Azad University, Neyshabur Branch, Neyshabur, Iran fatal to humans in the form of multi-antibiotic resistant bacteria. These bacteria are present in environmental sources (e.g., water, soil, and sediments) and can readily transfer their resistance to pathogenic bacteria via horizontal gene transfer, resulting in a global antibiotic resistance problem [3].

In the last two decades, progress has been made to address the antibiotic contamination problems in many environmental sources using various remediation technologies. Several physical and chemical degradation methods such as chemical oxidation, adsorption, membrane filtration, ozonation, photo-fenton, and bio-degradation methods such as activated sludge, membrane reactor, and fixed bed reactor treatment have been applied to many antibiotics including $\mathrm{TC}$ with the purpose of degrading them in environmental sources. However, these remediation technologies are highly condition-based (e.g., $\mathrm{pH}$, and molar ratio) and potentially expensive based on the concentration of the contaminant present in the environmental source (antibiotic) that needs to be degraded [4-9].

Removal of antibiotics by adsorption is one of the inexpensive methods with small technical difficulties. Many adsorbents have been widely used to remove tetracycline from wastewater such as carbon nanotubes [10], graphene 
oxide [11], activated carbon [12, 13], zeolites [14-16] and metal oxides [17]. Synthetic zeolite $13 \mathrm{X}$ is a common adsorbent which is composed of silicon-oxygen and aluminumoxygen tetrahedron connected by oxygen atoms. The uniform pore structure and high surface area make it an ideal sorbent. The cation exchange capacity is relatively high, which enhances the effect of surface modification on the adsorbent capacity of the sorbent $[18,19]$. Fe oxides are widely spread in ecosystems, and iron modified zeolites have been used for organic and heavy metal removal from wastewaters [20-23]. They show high affinity to TC compounds due to the surface complexation process [24, 25]. Iron ion could form a bridge between the zeolite and tetracycline molecule and enhance the adsorption process [26, 27].

The purpose of this work is to remove tetracycline using synthetic zeolite $13 \mathrm{X}$. The synthetic zeolite has been modified with trivalent iron. The effect of different operating parameters such as $\mathrm{pH}$, time, adsorbent dosage, etc. has been investigated.

\section{Materials and methods}

The zeolite used in this work is Na-13X which was purchased from IranZeolite. Tetracycline hydrochloride was purchased from Aldrich, $\mathrm{FeCl}_{3} \cdot 6 \mathrm{H}_{2} \mathrm{O}$ and $\mathrm{NaOH}$ from Merck Inc.

In order to prepare the treated zeolite, $3 \mathrm{~g}$ of zeolite was impregnated in $50 \mathrm{cc}$ solution of $40 \mathrm{mmol} \mathrm{FeCl}_{3}$. The solution was stirred at room temperature for $24 \mathrm{~h}$, separated and washed several times with deionized water and dried at $105^{\circ} \mathrm{C}$ overnight. The obtained samples were powdered and used for the adsorption experiments.

For the adsorption experiments, $50 \mathrm{ml}$ of tetracycline solution with different concentrations and specified amounts of sorbent were mixed using a shaker for $24 \mathrm{~h}$ to make sure it reaches the equilibrium state. After separation by centrifuge, the supernatant solution was collected for concentration measurement using UV-Vis spectroscopy at $357 \mathrm{~nm}$ wavelength. The $\mathrm{pH}$ of the solutions was adjusted using $0.1 \mathrm{M}$ $\mathrm{NaOH}$ and $\mathrm{HCl}$. To investigate the effect of $\mathrm{pH}$, experiments were carried out in the $\mathrm{pH}$ range of 2-9. For all the experiments, temperature was set to $30{ }^{\circ} \mathrm{C}$. For the kinetic experiments, $75 \mathrm{mg}$ of modified zeolite was added to $50 \mathrm{ml}$ of tetracycline solution (200 ppm). Each $15 \mathrm{~min}, 1 \mathrm{ml}$ of the solution was separated using a $0.22 \mu \mathrm{m}$ membrane filter and the tetracycline concentration was measured.
FESEM (TESCAN MIRA III), XRD (Philips PW 1730), XRF (Philips PW 1410), BET (BELSORP MINI II) and FTIR (Thermo AVATAR) analyses were performed for characterization of the sorbents. The XRD analysis was performed using the Philips PW 1730 instrument at an angle between 10 and 80 degrees. A glass tube with $20 \mathrm{~mm}$ diameter and $130 \mathrm{~mm}$ height was used for removal of tetracycline at continuous conditions. The tetracycline solution (200 ppm) was delivered using a peristatic pump at a flow rate of $1 \mathrm{ml} / \mathrm{min}$. The breakthrough curves were used to study the adsorption capacity of the sorbents.

\section{Results and discussion}

\section{Adsorbent characterization}

Table 1 shows the XRF results for raw and modified zeolites. An increase in Fe content of the modified zeolite is noticeable. In addition, the Na content decreases which may be due the exchange of the $\mathrm{Na}^{+}$ion with $\mathrm{Fe}^{3+}$ ion. It seems that part of $\mathrm{Fe}^{3+}$ is exchanged with $\mathrm{Na}^{+}$in the zeolite texture and other parts were precipitated in the form of $\mathrm{Fe}_{2} \mathrm{O}_{3}$.

To investigate the crystallinity of the sorbents and phase study, XRD analysis was carried out. Figure 1 shows the patterns for raw and modified zeolites. The characteristic peaks attributed to zeolite $13 \mathrm{X}$ can be seen at $2 \theta$ values of 12.5 , 17.7, 21.7, 27.2 and 33.5. For the modified zeolite, no sharp and clear peaks attributed to iron oxide can be detected. The large difference in the concentration of zeolite to $\mathrm{Fe}$ is one of the main reasons that decreases the intensity of Fe oxide peaks in comparison to the zeolite peaks [28].

Figure 2 presents the FESEM graphs for raw and modified zeolites. No considerable changes can be observed in the morphology of the two samples.

BET results showed that the specific surface area of the zeolite significantly increases after modification, from 25.72 to $98.82 \mathrm{~m}^{2} / \mathrm{g}$. Total pore volume also increases from 0.1811 to $0.2716 \mathrm{~cm}^{3} / \mathrm{g}$.

Infrared spectrum analysis was carried out on the $13 \mathrm{X}$ zeolite sample before and after modification and also after tetracycline adsorption to investigate the mechanism of adsorption (Fig. 3). After modification of zeolite, a new band around $597 \mathrm{~cm}^{-1}$ appeared which is related to the $\mathrm{Fe}-\mathrm{O}$ bond. In addition, some of the existing bands of $13 \mathrm{X}$ zeolite shifted such as the band of $439 \mathrm{~cm}^{-1}$ assigned to $\mathrm{Si}-\mathrm{O}$ bond that shifted to $431 \mathrm{~cm}^{-1}$ and the band of 609
Table 1 XRF results for raw and modified zeolites

\begin{tabular}{lllllllr}
\hline Sample & $\mathrm{SiO}_{2}$ & $\mathrm{Al}_{2} \mathrm{O}_{3}$ & $\mathrm{Fe}_{2} \mathrm{O}_{3}$ & $\mathrm{CaO}$ & $\mathrm{Na}_{2} \mathrm{O}$ & $\mathrm{Cl}$ & LOI \\
\hline Raw zeolite & 40.847 & 27.351 & 0.458 & 0.039 & 23 & - & 7 \\
M-zeolite & 40.969 & 27.036 & 8.445 & 0.073 & 8.349 & 2.3 & 12
\end{tabular}




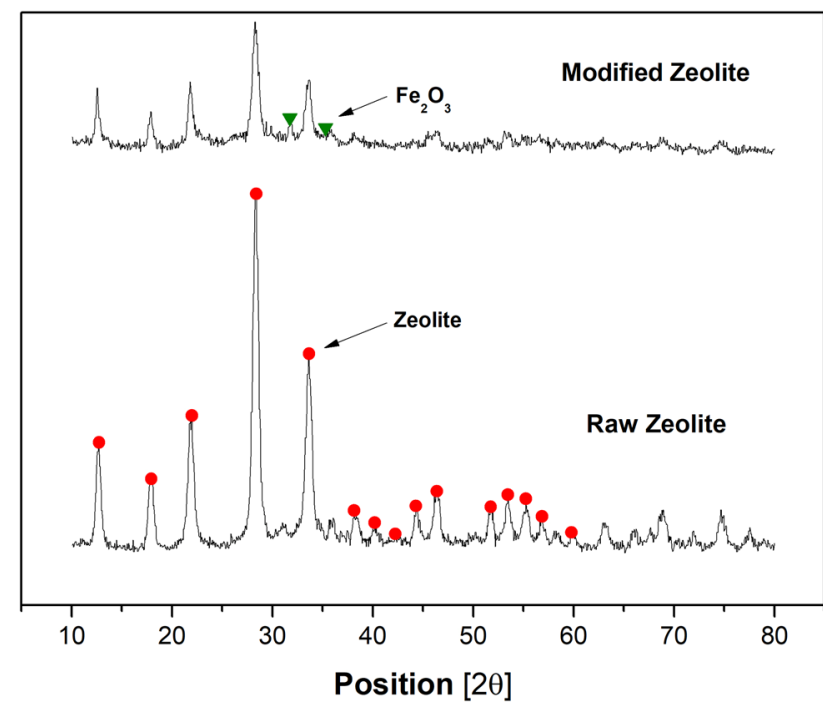

Fig. 1 XRD patterns of raw and modified zeolites

assigned to the Al-O bond that shifted to $605 \mathrm{~cm}^{-1}$. These changes indicate the formation of the $\mathrm{Fe}-\mathrm{O}$ bond on the zeolite through the interaction between the $\mathrm{Fe}$ ion and the $\mathrm{O}^{2-}$ anion of Si-O-Al. IR spectra of Fe-13X zeolite after TC adsorption change as a new band around 1462 assigned to vibration of the aromatic ring of TC appeared. The band of 1675 assigned to the $\mathrm{C}=\mathrm{O}$ amid group shifted to 1720 . It can be concluded that iron ion has interaction with the nitrogen atom of the amide group of TC.

Figure 4 presents a comparison between the raw and modified zeolites for tetracycline removal. The adsorption efficiency increases considerably after modification. The absorption percentage is obtained using the following equation:
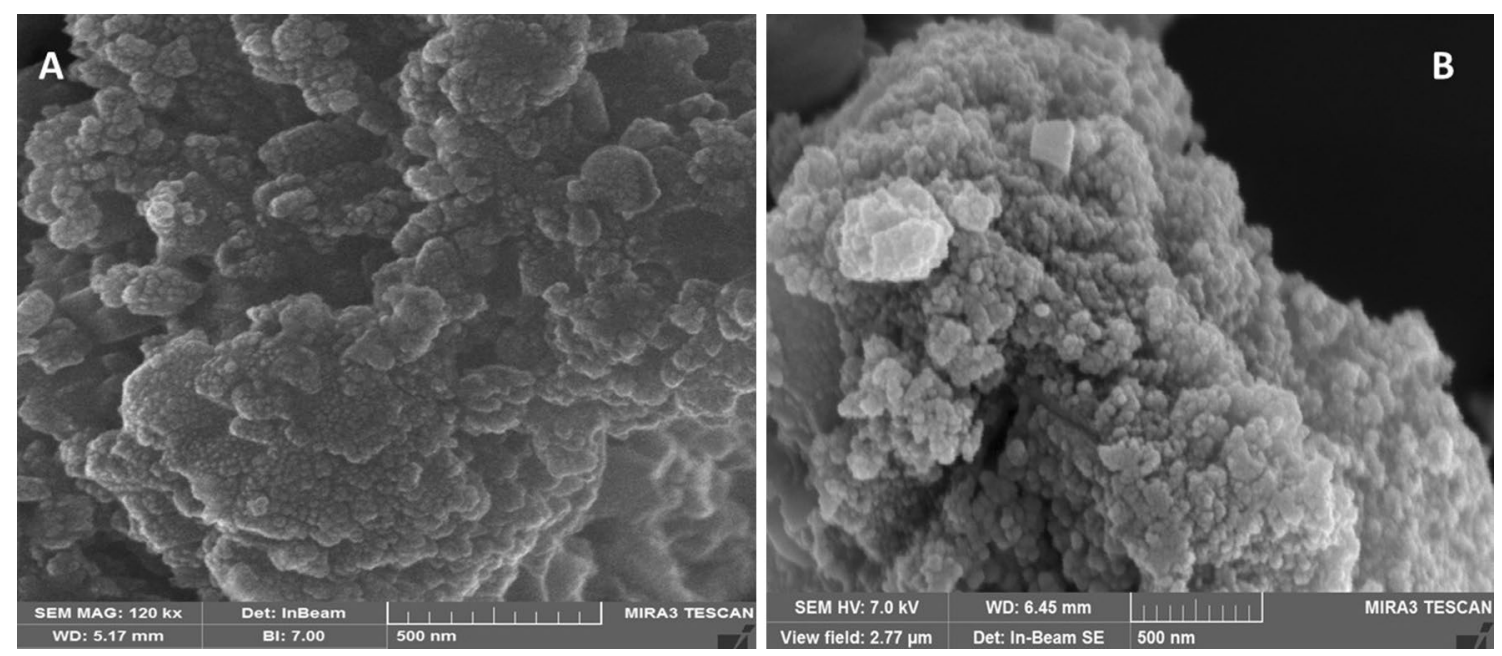

$\operatorname{Ad} \%=\frac{C_{0}-C_{\mathrm{f}}}{C_{0}} \times 100$.

The amount of tetracycline adsorbed per unit mass of zeolite is calculated as follows:

$q_{\mathrm{e}}=\frac{\left(C_{0}-C_{\mathrm{f}}\right) \times V}{m}$.

$C_{0}$ and $C_{\mathrm{f}}$ are the initial and final concentration of the solution in ppm, $V$ is the volume of solution in liters and $\mathrm{m}$ is the weight of the adsorbent in grams.

\section{Effect of sorbent dosage}

The effect of adsorbent weight on the adsorption capacity is shown in Fig. 4. It can be seen that for the adsorbent weight of $75 \mathrm{mg}$, the removal efficiency is nearly optimum (high enough and does not change considerably with increasing the sorbent weight). However, the adsorption capacity of sorbent decreases with increasing the sorbent dosage. This may be due to the fact that the ratio of the number of TC molecules in the solution to vacant sites of the sorbent decreases with increasing the sorbent weight. Thus, the probability of interaction between vacant sites and TC molecules decreases.

\section{Effect of pH}

The effect of $\mathrm{pH}$ on the efficiency of tetracycline removal by zeolite $13 \mathrm{X}$ is shown in Fig. 5.

Fig. 2 FESEM images of raw (a) and modified (b) zeolites 


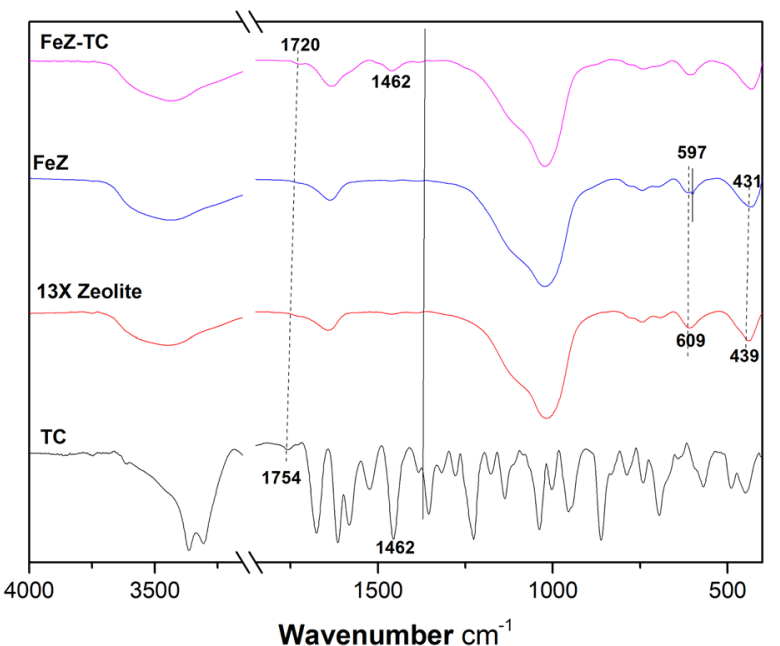

Fig. 3 IR spectra of TC, raw zeolite, modified zeolite, and modified zeolite after TC adsorption

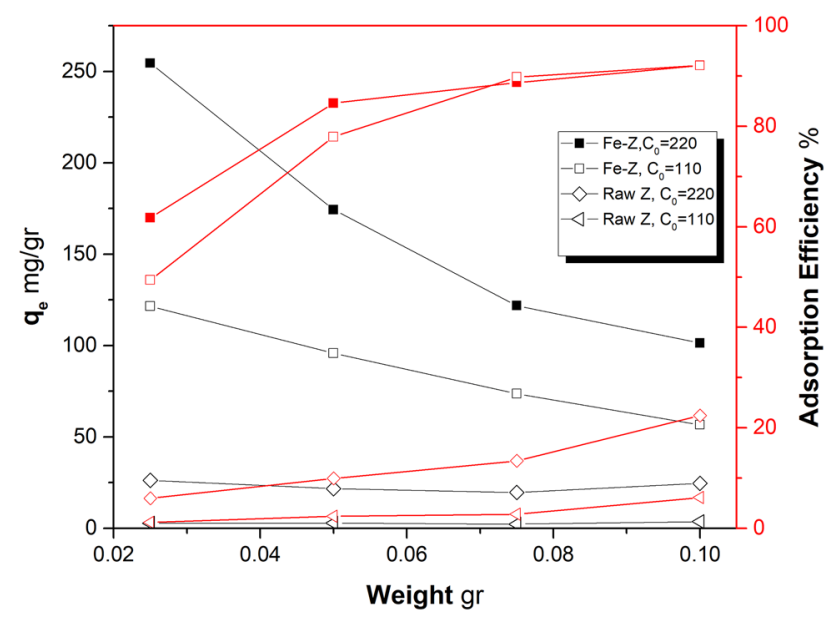

Fig. 4 Effect of sorbent dosage on the removal efficiency of tetracycline for raw and modified zeolites $\left(\mathrm{pH} 6, T=25^{\circ} \mathrm{C}\right.$, time $=24 \mathrm{~h}$ )

The effect of $\mathrm{pH}$ on the absorption capacity depends on the structure of tetracycline and the functional groups of the zeolite-iron composite surface. The results show that the removal of tetracycline strongly depends on the $\mathrm{pH}$ of the solution. This is due to the fact that tetracycline charges considerably change with $\mathrm{pH}$ as shown in Fig. 6. For $\mathrm{pH}$ below 3.3 , the dimethylammonium group is protonated, which results in tetracycline in +00 form. Between 3.3 and 7.7 , it is in the form of zwitterion +-0 . Above 7.7 , it is present as monovalent anion, +-- , or a divalent anion, $0--$.

On the other hand, deprotonation and protonation reactions of iron hydroxide coated on zeolite change the

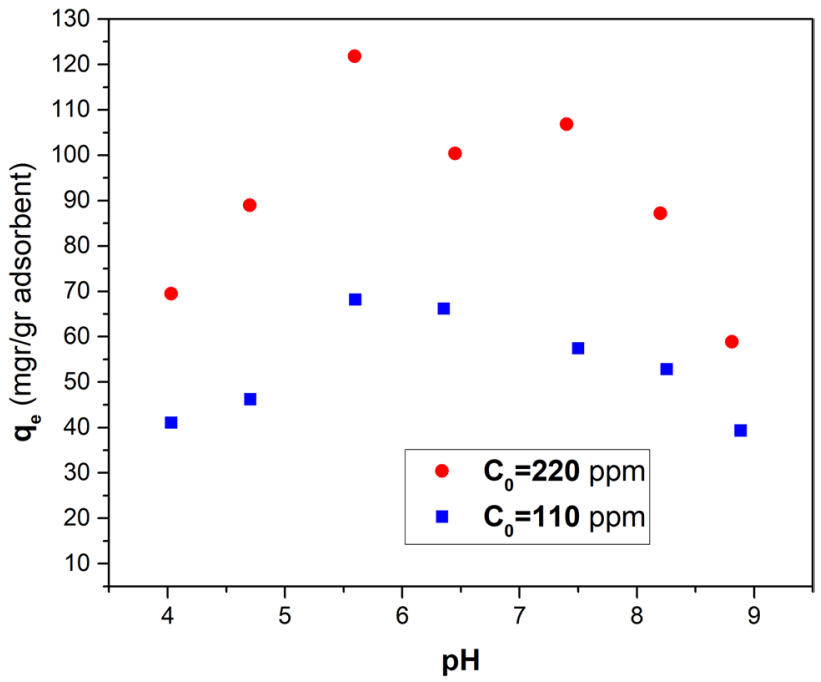

Fig. 5 Effect of $\mathrm{pH}$ on the removal efficiency of tetracycline by modified zeolite (sorbent weight $=0.075 \mathrm{~g}, T=25^{\circ} \mathrm{C}$, time $=24 \mathrm{~h}$ )

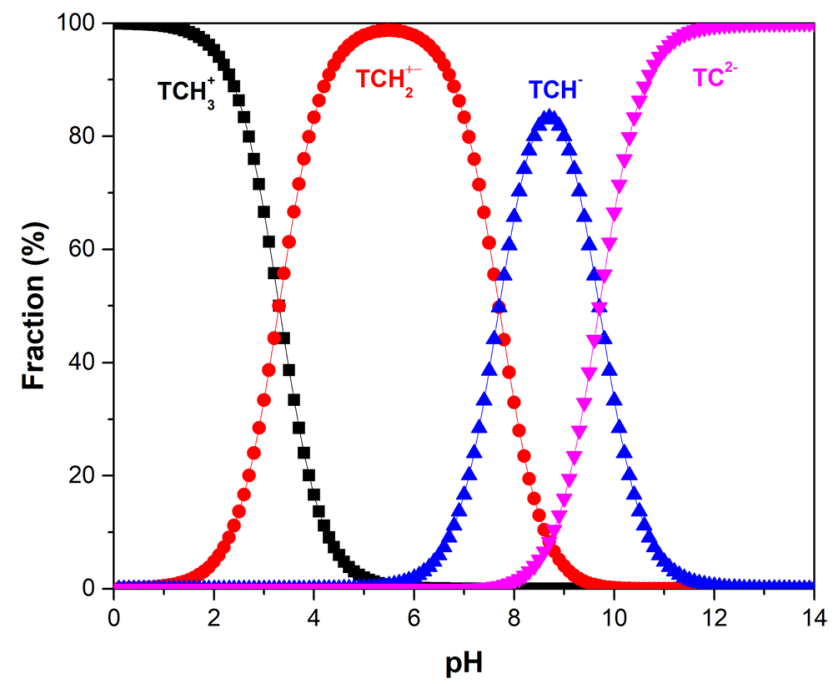

Fig. 6 Tetracycline dissociation under different $\mathrm{pH}$ values in aqueous solution

surface charge of the modified zeolite. Under the acidic condition, the surface charge is more positive and at alkaline condition, it becomes negatively charged [21]. This is in agreement with the fact that the $\mathrm{pH}_{\mathrm{zpc}}$ of modified zeolite was measured as 6.35 .

So, at acidic and alkaline conditions, electrostatic repulsion between tetracycline molecules and modified zeolite decreases the adsorption capacity. It seems that the best efficiency of modified sorbent for tetracycline removal is in the $\mathrm{pH}$ range of 5.5-6. 


\section{Kinetic experiments}

The rate of tetracycline adsorption on the modified zeolite was analyzed using different kinetic models (Lagergren, pseudosecond order, Elovich and diffusion model).

Figure 7a presents the effect of contact time on the adsorption efficiency. First order and second order equations were used to investigate the kinetics of adsorption. The pseudo first order rate equation is as follows:

$\frac{\mathrm{d} q}{\mathrm{~d} t}=k_{1}\left(q_{\mathrm{e}}-q\right)$.
Integrating Eq. (3) results in:

$\frac{\ln q_{\mathrm{e}}-q}{q_{\mathrm{e}}}=-k_{1} t$.

The pseudo-second order equation can be expressed as:

$\frac{\mathrm{d} q}{\mathrm{~d} t}=k_{2}\left(q_{\mathrm{e}}-q\right)^{2}$.

Integrating Eq. (5) gives:

$\frac{t}{q}=\frac{1}{k_{2} q_{\mathrm{e}}^{2}}+\frac{1}{q_{\mathrm{e}}} t$.
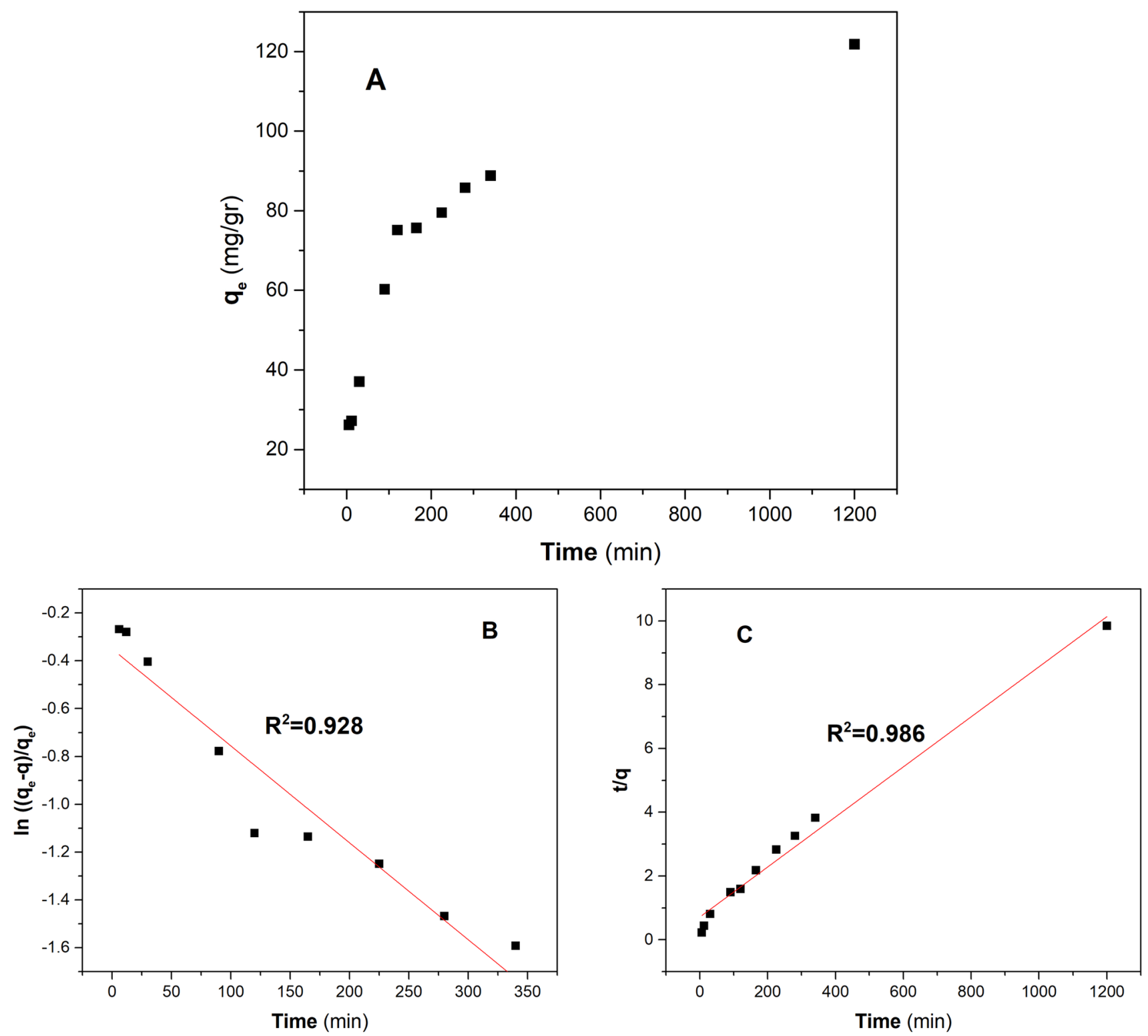

Fig. 7 a tetracycline concentration in the solution versus time, b linear form of first-order kinetic, $\mathbf{c}$ linear form for second-order kinetic (sorbent weight $=0.075 \mathrm{~g}, T=25^{\circ} \mathrm{C}$, time $=24 \mathrm{~h}$ ) 
By plotting $\frac{\ln q_{\mathrm{e}}-q}{q_{\mathrm{e}}}$ for the first order and $\frac{t}{q}$ for second order versus $t$, the lines with slopes of $-k_{1}$ and $\frac{q}{q_{\mathrm{e}}}$ are obtained.

Figures $7 \mathrm{~b}$ and $7 \mathrm{c}$ show the results of first and second order kinetics for tetracycline removal by the modified zeolite. As can be seen, the second order kinetics is more consistent with the experimental data. The Elovich model was usually applied to systems in which the solid surface is heterogeneous. The equation is formulated as [29, 30]:

$\frac{\mathrm{d} q}{\mathrm{~d} t}=a \exp \left(-b q_{\mathrm{t}}\right)$.

It can be linearized and simplified as:

$q_{\mathrm{t}}=\frac{1}{b} \ln (a b)+\frac{1}{b} \ln t$

Figure 8a shows the linear form of the Elovich equation. According to the dimensionless form of the Elovich equation (Eq. 9) developed by Wu et al. [30], $R_{\mathrm{E}}$ is defined as the approaching equilibrium factor ranging between 0.02 and 0.3:

$\frac{q_{\mathrm{t}}}{q_{\mathrm{ref}}}=R_{\mathrm{E}} \ln \left(\frac{t}{t_{\mathrm{ref}}}\right)+1$.

Using Eq. 9, $R_{\mathrm{E}}$ was calculated as 0.15 . This value indicates that the kinetic of tetracycline adsorption on zeolite is in zone II and the curve rises mildly.

The overall rate of adsorption in a solid-liquid system could be described by three steps in series: (1) transport of adsorbent from the bulk of liquid to the solid surface; (2) diffusion of adsorbate from the surface through the pores of adsorbent; (3) adsorption on the vacant sites of the adsorbent.
Generally, the last step is very rapid and the mass transfer steps are the rate controlling stages [31]. The equation used for studying the diffusion regime is as follows:

$q=k_{\mathrm{d}} t^{1 / 2}+C$.

$k_{\mathrm{d}}$ is the rate constant for intra-particle diffusion. $C$ is a constant that represents the effect of external mass transfer. The higher the intercept $(C)$, the bigger the effect of boundary layer resistance.

Figure $8 \mathrm{~b}$ presents the diffusion stages of adsorption. The first section of the plot is related to the external mass transfer resistance and the latter linear portion represents the intraparticle diffusion.

\section{Adsorption isotherms}

Isotherm graphs examine the equilibrium absorbance at different concentrations and test their compatibility with the adsorption theories.

The Langmuir theory in the linear form is usually expressed as:

$\frac{1}{q_{\mathrm{e}}}=\frac{1}{q_{\mathrm{m}}}+\frac{1}{q_{\mathrm{m}} b c_{\mathrm{e}}}$,

where $q_{\mathrm{m}}$ is the maximum single-layer absorption capacity in $\mathrm{mg} \mathrm{g}^{-1}, C_{\mathrm{e}}$ is the equilibrium concentration of TC in the solution $\left(\mathrm{mg} \mathrm{L}^{-1}\right)$ and $b$ is the Langmuir constant.

Another well-known model is the Freundlich isotherm, which assumes that the surface energy of the various active points are different and expressed as follows:

$q_{\mathrm{e}}=k c_{\mathrm{e}}^{1 / n}$.
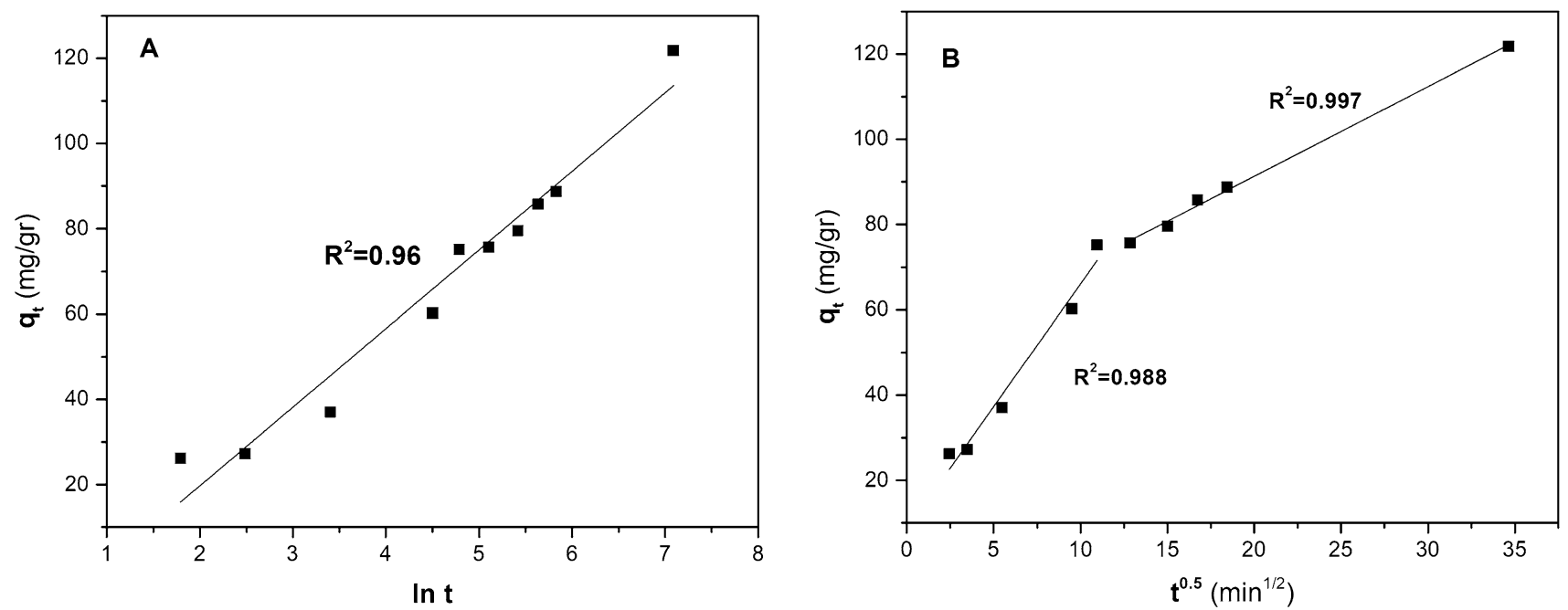

Fig. 8 a Elovich model and $\mathbf{b}$ intraparticle diffusion plot for adsorption of tetracycline on the modified zeolite 
Table 2 Fitting parameters for the adsorption isotherms

\begin{tabular}{|c|c|c|c|c|c|c|c|c|c|c|}
\hline \multicolumn{3}{|l|}{ Langmuir } & \multicolumn{3}{|c|}{ Freundlich } & \multicolumn{3}{|c|}{$\mathrm{D}-\mathrm{R}$} & \multicolumn{2}{|c|}{ Temkin } \\
\hline$q_{\mathrm{m}}\left(\mathrm{mg} \mathrm{g}^{-1}\right)$ & $b$ & $R^{2}$ & $k$ & $n$ & $R^{2}$ & $q_{\mathrm{m}}$ & $B$ & $R^{2}$ & $k_{\mathrm{T}}$ & $R^{2}$ \\
\hline 204 & 0.053 & 0.9958 & 48.32 & 3.85 & 0.9273 & 167 & $2 \times 10^{-5}$ & 0.83 & 35.7 & 0.975 \\
\hline
\end{tabular}

By linearizing the equation above, the following equation is obtained:

$\ln q_{\mathrm{e}}=\ln k+\frac{1}{n} \ln c_{\mathrm{e}}$,

where $k$ and $n$ are the constants of the Freundlich equation, and $C_{\mathrm{e}}$ and $q_{\mathrm{e}}$ are the equilibrium concentrations of TC and the adsorption capacity.

The Dubinin-Radushkevich (DR) isotherm is another equation which has been widely used to correlate the experimental data of different microporous adsorbents [32, 33]. The linear form of D-R equation is as follows:

$\ln q_{e}=\ln q_{m}-\beta \varepsilon^{2}, \varepsilon=R \operatorname{Tln}\left(1+\frac{1}{C_{e}}\right)$

where $q_{\mathrm{e}}$ is the amount of tetracycline adsorbed at equilibrium state, $q_{\mathrm{m}}$ is the maximum adsorption capacity, $\beta$ is the activity coefficient and $\varepsilon$ is the Polanyi potential.

The Temkin isotherm assumes the linear decrease of the heat of adsorption of all molecules in a layer with increasing the surface coverage $[34,35]$. The linear form is expressed as:

$q_{\mathrm{e}}=k_{\mathrm{T}} \ln f+k_{\mathrm{T}} \ln C_{\mathrm{e}}$.

where $k_{\mathrm{T}}$ and $f$ are constant. Table 2 presents the fitting parameters calculated by different equations. Although the results of models can be used to explain the results, the Langmuir model best fits the experimental data (Fig. 9).

The results show that the experimental data matched the Langmuir equation well and $R^{2}$ is close to 1 . Thus, the adsorption of TC on the modified zeolite is a selective monolayer adsorption due to the formation of a chemical bond. The maximum adsorption capacity of modified zeolite for tetracycline is $204 \mathrm{mg} \mathrm{g}^{-1}$ which is about four times greater than unmodified zeolite. Table 3 presents a comparison between the adsorption capacities of different adsorbents for the removal of antibiotics reported in the literature.

\section{Column study}

Figure 10 shows the result of column experiments for the raw and modified zeolites. The breakthrough curves have a typical ' $S$ ' shape. The raw zeolite shows small retention for tetracycline (about 10\%). Fe-modified zeolite, however, shows $100 \%$ removal of tetracycline for the first 10 bed volumes, despite the high concentration of tetracycline, which makes it possible for use in pharmaceutical wastewater treatment.

\section{Conclusion}

The following conclusions can be drawn from the results of this work:

1. Adsorption of TC on the modified zeolite is strongly $\mathrm{pH}$ dependent and the best results can be reached at a $\mathrm{pH}$ range of 5.5-6.

2. The Langmuir isotherm can be best fitted with the experimental data with an adsorption capacity as high as 200 $\mathrm{mg} \mathrm{g}^{-1}$, which is in agreement with the experimental results.

3. Modification of zeolite $13 \mathrm{X}$ with $\mathrm{Fe}^{3+}$ significantly increases the adsorption capacity of tetracycline.

4. The kinetics of adsorption follows the second order model. Also, the diffusion model is well fitted with the experimental data showing that external mass transfer and intra-particle diffusion play an important role on the overall rate of adsorption.

5. The modified zeolite shows good performance for the removal of tetracycline in the fixed bed column. 

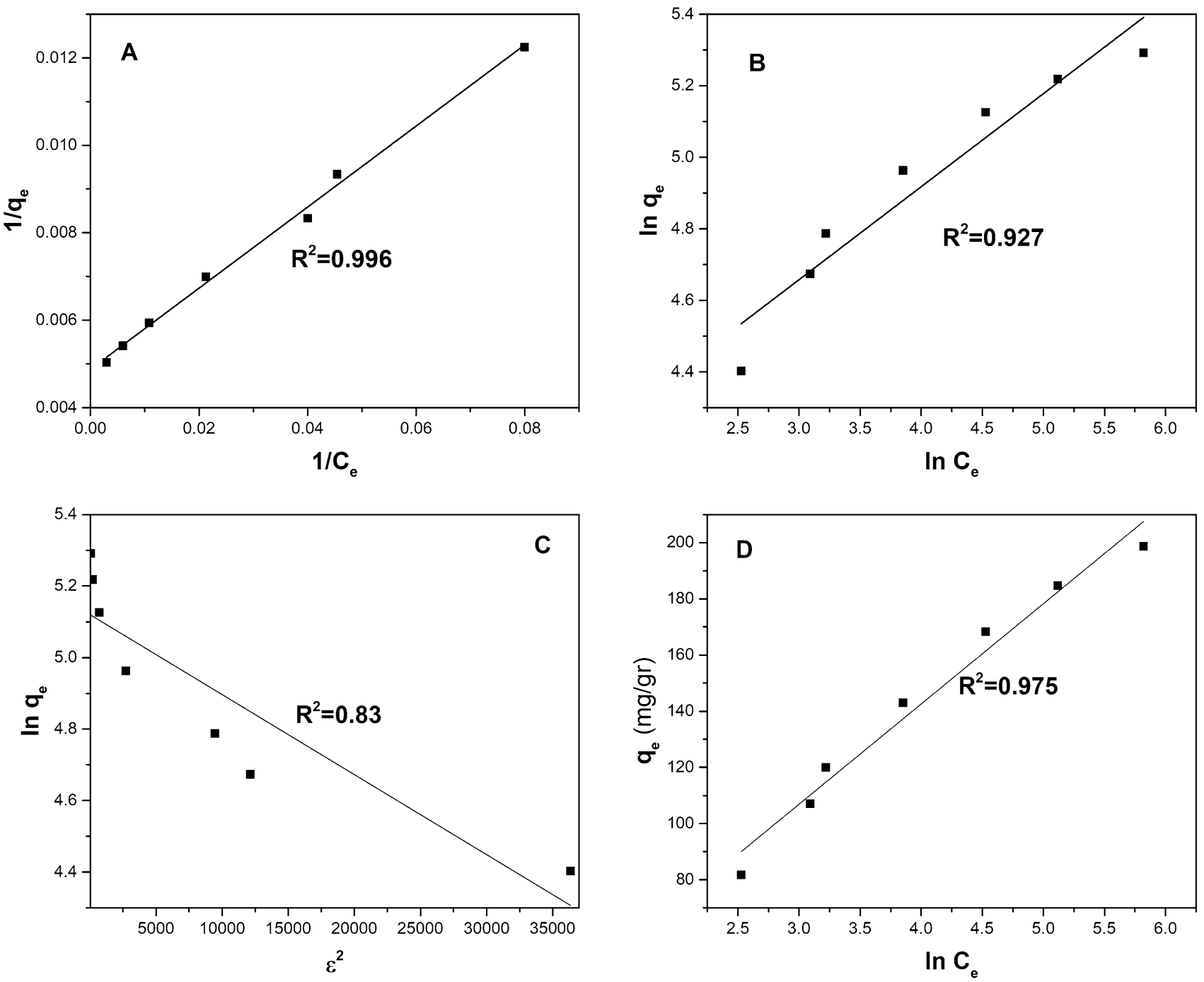

Fig. 9 Correlation of experimental data with a Langmuir isotherm and $\mathbf{b}$ Freundlich isotherm, $\mathbf{c}$ D-R isotherms and $\mathbf{d}$ Temkin isotherm

Table 3 Comparison between different adsorbents for tetracycline removal from solutions

\begin{tabular}{llllll}
\hline Adsorbent & Contaminant & $C_{0}(\mathrm{ppm})$ & Time $(\mathrm{min})$ & $\mathrm{q}_{\max }(\mathrm{mg} / \mathrm{g})$ & References \\
\hline Fe modified zeolite & Tetracycline & $100-600$ & 400 & 200 & Current work \\
MWCNT & Tetracycline & 50 & 20 & 150 & {$[10]$} \\
Graphene oxide & Tetracycline & $8-333$ & 90 & 313 & {$[11]$} \\
AC (beet pulp) & Tetracycline & 200 & 720 & 280 & {$[36]$} \\
AC (macadamia nut shell) & Tetracycline & 500 & 180 & 410 & {$[37]$} \\
GO functionalized magnetic particle & Tetracycline & $10-50$ & 10 & 39.1 & {$[38]$} \\
Fe-Mn oxide & Tetracycline & $44.4-222.2$ & 840 & 90 & {$[17]$} \\
\hline
\end{tabular}




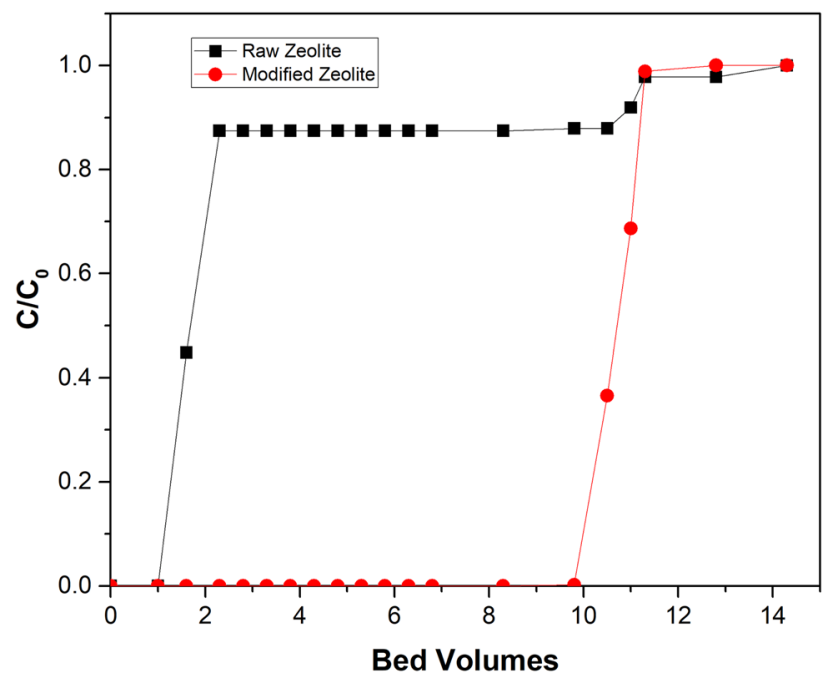

Fig. 10 Breakthrough curves for raw and modified zeolites $\left(T=25{ }^{\circ} \mathrm{C}, C_{0}=220 \mathrm{ppm}\right)$

Open Access This article is distributed under the terms of the Creative Commons Attribution 4.0 International License (http://creativeco mmons.org/licenses/by/4.0/), which permits unrestricted use, distribution, and reproduction in any medium, provided you give appropriate credit to the original author(s) and the source, provide a link to the Creative Commons license, and indicate if changes were made.

\section{References}

1. Kümmerer K (2009) Antibiotics in the aquatic environmenta review-part II. Chemosphere 75(4):435-441. https://doi. org/10.1016/j.chemosphere.2008.12.006

2. Javid A, Mesdaghinia A, Nasseri S, Mahvi AH, Alimohammadi M, Gharibi H (2016) Assessment of tetracycline contamination in surface and groundwater resources proximal to animal farming houses in Tehran, Iran. J Environ Health Sci 14(1):4. https://doi. org/10.1186/s40201-016-0245-Z

3. Martinez JL (2009) Environmental pollution by antibiotics and by antibiotic resistance determinants. Environ Pollut 157(11):28932902. https://doi.org/10.1016/j.envpol.2009.05.051

4. Gómez-Pacheco CV, Sánchez-Polo M, Rivera-Utrilla J, LópezPeñalver J (2011) Tetracycline removal from waters by integrated technologies based on ozonation and biodegradation. Chem Eng J 178:115-121. https://doi.org/10.1016/j.cej.2011.10.023

5. Pan S-F, Zhu M-P, Chen JP, Yuan Z-H, Zhong L-B, Zheng Y-M (2015) Separation of tetracycline from wastewater using forward osmosis process with thin film composite membrane-implications for antibiotics recovery. Sep Purif Technol 153:76-83. https ://doi.org/10.1016/j.seppur.2015.08.034

6. Rayaroth MP, Aravind UK, Aravindakumar CT (2016) Degradation of pharmaceuticals by ultrasound-based advanced oxidation process. Environ Chem Lett 14(3):259-290. https://doi. org/10.1007/s10311-016-0568-0

7. Shah AD, Huang C-H, Kim J-H (2012) Mechanisms of antibiotic removal by nanofiltration membranes: model development and application. J Membr Sci 389:234-244. https://doi. org/10.1016/j.memsci.2011.10.034

8. Shi Y-J, Wang X-H, Qi Z, Diao M-H, Gao M-M, Xing S-F, Wang S-G, Zhao X-C (2011) Sorption and biodegradation of tetracycline by nitrifying granules and the toxicity of tetracycline on granules. J Hazard Mater 191(1):103-109. https://doi. org/10.1016/j.jhazmat.2011.04.048

9. Wang Y, Zhang H, Chen L, Wang S, Zhang D (2012) Ozonation combined with ultrasound for the degradation of tetracycline in a rectangular air-lift reactor. Sep Purif Technol 84:138-146. https ://doi.org/10.1016/j.seppur.2011.06.035

10. Zhang L, Song X, Liu X, Yang L, Pan F, Lv J (2011) Studies on the removal of tetracycline by multi-walled carbon nanotubes. Chem Eng J 178:26-33. https://doi.org/10.1016/j.cej.2011.09.127

11. Gao Y, Li Y, Zhang L, Huang H, Hu J, Shah SM, Su X (2012) Adsorption and removal of tetracycline antibiotics from aqueous solution by graphene oxide. J Colloid Interface Sci 368(1):540 546. https://doi.org/10.1016/j.jcis.2011.11.015

12. Marzbali MH, Esmaieli M, Abolghasemi H, Marzbali MH (2016) Tetracycline adsorption by $\mathrm{H}_{3} \mathrm{PO}_{4}$-activated carbon produced from apricot nut shells: a batch study. Process Saf Environ 102:700-709. https://doi.org/10.1016/j.psep.2016.05.025

13. Sayğılı H, Güzel F (2016) Effective removal of tetracycline from aqueous solution using activated carbon prepared from tomato (Lycopersicon esculentum Mill.) industrial processing waste. Ecotoxicol Environ Saf 131:22-29. https://doi.org/10.1016/j.ecoen v.2016.05.001

14. de Sousa DNR, Insa S, Mozeto AA, Petrovic M, Chaves TF, Fadini PS (2018) Equilibrium and kinetic studies of the adsorption of antibiotics from aqueous solutions onto powdered zeolites. Chemosphere 205:137-146. https://doi.org/10.1016/j.chemospher e. 2018.04 .085

15. Guo Y, Huang W, Chen B, Zhao Y, Liu D, Sun Y, Gong B (2017) Removal of tetracycline from aqueous solution by MCM-41-zeolite A loaded nano zero valent iron: synthesis, characteristic, adsorption performance and mechanism. J Hazard Mater 339:2232. https://doi.org/10.1016/j.jhazmat.2017.06.006

16. Liu M, An D, Hou L-a, Yu S, Zhu Y (2015) Zero valent iron particles impregnated zeolite $\mathrm{X}$ composites for adsorption of tetracycline in aquatic environment. RSC Adv 5(125):103480-103487. https://doi.org/10.1039/C5RA21715F

17. Liu H, Yang Y, Kang J, Fan M, Qu J (2012) Removal of tetracycline from water by $\mathrm{Fe}-\mathrm{Mn}$ binary oxide. J Environ Sci 24(2):242-247. https://doi.org/10.1016/S1001-0742(11)60763-8

18. McEwen J, Hayman J-D, Ozgur Yazaydin A (2013) A comparative study of $\mathrm{CO}_{2}, \mathrm{CH}_{4}$ and $\mathrm{N}_{2}$ adsorption in ZIF-8, Zeolite-13X and BPL activated carbon. Chem Phys 412:72-76. https://doi. org/10.1016/j.chemphys.2012.12.012

19. Oh KS, Woo SI (2007) Validation of the catalytic properties of $\mathrm{Cu}-\mathrm{Os} / 13 \mathrm{X}$ using single fixed bed reactor in selective catalytic reduction of NO. Appl Surf Sci 254(3):677-681. https://doi. org/10.1016/j.apsusc.2007.05.096

20. Du G, Li Z, Liao L, Hanson R, Leick S, Hoeppner N, Jiang W-T (2012) $\mathrm{Cr}(\mathrm{VI})$ retention and transport through $\mathrm{Fe}(\mathrm{III})$-coated natural zeolite. J Hazard Mater 221-222:118-123. https://doi. org/10.1016/j.jhazmat.2012.04.016

21. Jeon C-S, Baek K, Park J-K, Oh Y-K, Lee S-D (2009) Adsorption characteristics of $\mathrm{As}(\mathrm{V})$ on iron-coated zeolite. J Hazard Mater 163(2):804-808. https://doi.org/10.1016/j.jhazmat.2008.07.052

22. Kragović M, Daković A, Marković M, Krstić J, Gatta GD, Rotiroti N (2013) Characterization of lead sorption by the natural and Fe(III)-modified zeolite. Appl Surf Sci 283:764-774. https://doi. org/10.1016/j.apsusc.2013.07.016

23. Melián-Cabrera I, Kapteijn F, Moulijn JA (2005) Innovations in the synthesis of Fe-(exchanged)-zeolites. Catal Today 110(3):255263. https://doi.org/10.1016/j.cattod.2005.09.040

24. Figueroa RA, MacKay AA (2005) Sorption of oxytetracycline to iron oxides and iron oxide-rich soils. Environ Sci Technol 39(17):6664-6671. https://doi.org/10.1021/es0480441 
25. Machado FC, Demicheli C, Garnier-Suillerot A, Beraldo H (1995) Metal complexes of anhydrotetracycline. 2. Absorption and circular dichroism study of $\mathrm{Mg}(\mathrm{II})$, AMID, and Fe(III) complexes. Possible influence of the $\mathrm{Mg}$ (II) complex on the toxic side effects of tetracycline. J Inorg Biochem 60(3):163-173. https://doi. org/10.1016/0162-0134(95)00017-i

26. Figueroa RA, Leonard A, MacKay AA (2004) Modeling tetracycline antibiotic sorption to clays. Environ Sci Technol 38(2):476483. https://doi.org/10.1021/es0342087

27. Hsu L-C, Liu Y-T, Syu C-H, Huang M-H, Tzou Y-M, Teah HY (2018) Adsorption of tetracycline on Fe (hydr)oxides: effects of $\mathrm{pH}$ and metal cation $\left(\mathrm{Cu}^{2+}, \mathrm{Zn}^{2+}\right.$ and $\left.\mathrm{Al}^{3+}\right)$ addition in various molar ratios. R Soc Open Sci 5(3):171941. https://doi. org/10.1098/rsos.171941

28. Jamalluddin NA, Abdullah AZ (2014) Low frequency sonocatalytic degradation of Azo dye in water using Fe-doped zeolite Y catalyst. Ultrason Sonochem 21(2):743-753. https://doi. org/10.1016/j.ultsonch.2013.10.008

29. Juang R-S, Chen M-L (1997) Application of the Elovich equation to the kinetics of metal sorption with solvent-impregnated resins. Ind Eng Chem Res 36(3):813-820. https://doi.org/10.1021/ie960 $351 \mathrm{f}$

30. Wu F-C, Tseng R-L, Juang R-S (2009) Characteristics of Elovich equation used for the analysis of adsorption kinetics in dyechitosan systems. Chem Eng J 150(2):366-373. https://doi. org/10.1016/j.cej.2009.01.014

31. Kalavathy MH, Karthikeyan T, Rajgopal S, Miranda LR (2005) Kinetic and isotherm studies of $\mathrm{Cu}$ (II) adsorption onto $\mathrm{H}_{3} \mathrm{PO}_{4}$-activated rubber wood sawdust. J Colloid Interf Sci 292(2):354-362. https://doi.org/10.1016/j.jcis.2005.05.087

32. Kakavandi B, Raofi A, Peyghambarzadeh SM, Ramavandi B, Niri MH, Ahmadi M (2018) Efficient adsorption of cobalt on chemical modified activated carbon: characterization, optimization and modeling studies. Desalin Water Treat 111:310-321
33. Kapoor A, Ritter JA, Yang RT (1989) On the Dubinin-Radushkevich equation for adsorption in microporous solids in the Henry's law region. Langmuir 5(4):1118-1121. https://doi.org/10.1021/ la00088a043

34. Ayawei N, Ebelegi AN, Wankasi D (2017) Modelling and interpretation of adsorption isotherms. J Chem 2017:11. https://doi. org/10.1155/2017/3039817

35. Inyinbor AA, Adekola FA, Olatunji GA (2016) Kinetics, isotherms and thermodynamic modeling of liquid phase adsorption of Rhodamine B dye onto Raphia hookerie fruit epicarp. Water Resour Ind 15:14-27. https://doi.org/10.1016/j.wri.2016.06.001

36. Torres-Pérez J, Gérente C, Andrès Y (2012) Sustainable activated carbons from agricultural residues dedicated to antibiotic removal by adsorption. Chin J Chem Eng 20(3):524-529. https:// doi.org/10.1016/S1004-9541(11)60214-0

37. Martins AC, Pezoti O, Cazetta AL, Bedin KC, Yamazaki DAS, Bandoch GFG, Asefa T, Visentainer JV, Almeida VC (2015) Removal of tetracycline by $\mathrm{NaOH}$-activated carbon produced from macadamia nut shells: kinetic and equilibrium studies. Chem Eng J 260:291-299. https://doi.org/10.1016/j.cej.2014.09.017

38. Lin Y, Xu S, Li J (2013) Fast and highly efficient tetracyclines removal from environmental waters by graphene oxide functionalized magnetic particles. Chem Eng J 225:679-685. https://doi. org/10.1016/j.cej.2013.03.104

Publisher's Note Springer Nature remains neutral with regard to jurisdictional claims in published maps and institutional affiliations. 